\title{
Project-based learning resources Transitioning skills to experience and application
}

I n the one-shot world of library instruction, the thought of producing an actual product after an hour of instruction seems to be an improbable, if not impossible, task. However, the change in the expectation in the last ten years concerning the deepening understanding of instructional design, learning outcomes, assessment and evaluation, and embedded curriculum has led to new frontiers (and challenges) in how, why, and what librarians teach. The precious one hour of library instruction should be no more. A new horizon of deeper learning, strategizing and cultivating critical thoughts, and framing the legitimate work as the new paradigm can have a place in our professional culture.

Taking a cue from K-12, higher education curriculum, and andragogy has and continues to evolve from strict structures and lecture-based models (think busy-work worksheets), to interactive and participatory classrooms, which require not only risk-taking from administration and educators, but from students ready to reflect on their innate abilities and skills, broadening their interest levels through student-driven, community-based projects.

Project-based learning (PBL), as a fresh perspective on the learning process and skill acquisition, has elements to satisfy even the most reluctant of learners: responsibilities for the outcome lie in their ability and proclivity for a topic or problem posed, peer collaboration, recognizing their needs and strengths, and interactions with the world around them for legitimate, applicable outcomes.
Where does the librarian's role integrate with enriched, active learning when it's difficult to carve out more than one visit to the classroom? How does the project (which may take days or weeks to create) have a place in the one-shot world? Through PBL, the librarian is there from the inception of the project, throughout the entirety of skill-building, researching, developing a mode of delivery, and ultimately the evaluation of the feasible "solution" for the real-world issue.

PBL also aims to satisfy many guiding information literacy skills and standards, as well as a high-impact educational practices, ${ }^{1}$ through shared experiences, undergraduate research, and collaborative assignments and projects.

As applicable to the ACRL "Framework for Information Literacy for Higher Education" (2016), it provides deep collaboration not only through faculty-librarian partnerships, but transformational skill-building and understanding of concepts, context, and community. PBL can truly be the most rewarding experience, when given the chance to lead this type of learning model.

Here are some of the guiding materials and resources that can be both inspiration and application on the PBL path.

Rhonda Huisman is director of university library services at Marian University in Indianapolis, Indiana, email: rhuisman@marian.edu

(C) 2017 Rhonda Huisman 


\section{Learning theories and design}

- Inquiry-Based Learning and Guided

Inquiry. Hosted by the CCTE (Community Center for Teaching Excellence) and Monroe Community College (funded by the U.S. Department of Education, FIPSE) this site offers blogs, teaching resources, and connections between $\mathrm{K}-12$ educational models through the transition to higher education. Included is a glossary of theories and methodologies, with evidencebase and literature resources related to inquiry-based learning. Access: http://www. communitycenterforteachingexcellence. org/inquiry-based-learning/.

- Kathy Schrock's Authentic Student Learning. Kathy Schrock is a mainstay in the education world, with more than 40 years of experience in lesson plans, assessment, educational technology, and instructional design, this site (and many accompanying sites including her blog) offers practical tips and tricks in the classroom, and adapting

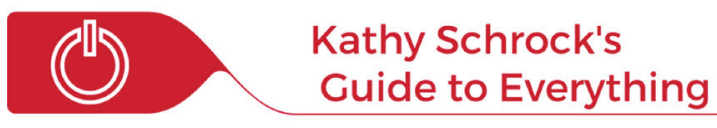

instructional technologies for all levels of students, from $\mathrm{K}-12$ through higher education, as well as professional development. Access: http://www.schrockguide.net/authentic -learning.html.

- Learning: Theory and Research. Serving as a guide through multiple facets of learning theory, education, psychology, and anthropology, this site supports the graduate student instructors at University of CaliforniaBerkeley and serves as a primer for evaluating and improving teaching through basic information on Skinner, Watson, and Piaget, as well as encyclopedic entries for concepts, research, and theories on intellectual, behavorial, and educational development. Access: http://gsi.berkeley.edu/gsi-guide -contents/learning-theory-research/.

\section{Problem and inquiry-based learning}

- AIBL. The Academy of Inquiry-Based
Learning (AIBL) focuses on the principles and practices of inquiry-based learning (IBL), which is defined as the

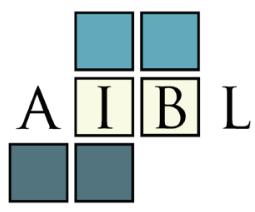
transformation of the teacher at the center of the instructional environment, to a studentcentered learning experience. This site offers support for participants in the form of workshops, small grants, resources, visiting speakers, and an active blog with weekly tips and reading suggestions for those heading down the IBL (or PBL) path. Access: http://www. inquirybasedlearning.org/.

- Gwenna Moss Centre for Teaching Effectiveness. The University of Saskatchewan hosts an engaging site filled with multiple layers of pedagogies (urban community-based, classroom, landbased, and Aboriginal), which offers a wealth of diverse perspectives and information to accompany the planning and implementation phases of PBL. Of particular note is the section on "Experiential Learning," which delves deeper into community engagement, fieldbased learning, and use of innovative technology. Access: http://www.usask.ca /gmcte/.

- The Teaching Channel: InquiryBased Teaching. While much of the content on the Teaching Channel is focused on elementary and secondary education, it has real-world examples of how to engage with students in inquiry-based discussions and texts, with feedback and testimonials from educators on how they view the students and their experience, recognizing their educational input and diversity, through confidence-building opportunities in the classroom. Access: https://www. teachingchannel.org/videos/reasons-for -inquiry-based-teaching.

\section{Building the curriculum}

- ASCD. Starting as the Association for Supervision and Curriculum Development (ASCD) in 1943, ASCD develops and delivers 
innovative programs and publications. While their focus is more typically K-12 centered, they emphasize teaching and learning best practices, transformational leadership, and redefining student success, including resources on PBL: "Seven Essentials for ProjectBased Learning" by John Larmer and John R. Mergnedoller and "Setting the Standard for Project-Based Learning: A Proven Approach to Rigorous Classroom Instruction" (http://www.ascd.org/Publications/Books /Overview/Setting-the-Standard-for-Project -Based-Learning.aspx). Access: http://www. ascd.org/Default.aspx.

- BIE (Buck Institute for Education). Known in instructional circles as the "go-to" resource for PBL, the Buck Institute for Education was started more than 25 years ago funded through the Buck Trust. Beginning as the Marin Educational Institute, they began as a small series of educational research projects, including a teaching handbook and benchmarks for quality and progress in the classrooms. The BIE connects teachers, administrators, and teacher preparation programs developing models to design, practice, and assess PBL. Access: http://www.bie.org/.

- Edutopia, Project-Based Learning. Edutopia offers the basic building blocks for PBL, through multimedia content, blog posts, resources, and instructional practice updates that reflect current design and curricular models situated in K-12 examples, but is not without practical tips and guidelines for the academic set. The history of PBL, studies on PBL effectiveness, and use of popular culture and social media in PBL. Access: http://www.edutopia.org /project-based-learning.

- The Power of Project Learning (Scholastic). Remember the book fairs and fundraisers in your school library and elementary classrooms? Scholastic has branched out to include professional development tools and materials, and in the Administrator section of their online magazine, Wayne D'Orio's article "The Power of Project-Based Learning" breaks down how schools and libraries can collaborate on this powerful pedagogical model. Additional curricular plans, resources, and activities are also available. Access: http://www.scholastic.com /browse $/$ article.jsp?id=3751748\&eml=SSO / a ff/ $20140501 /$ skimlinks / ba n ner/CJ/affiliate/////11837433/\&cj_ linkd=11837433\&cj_webid=3662453\&cj_si d=skim725X212064Xcb09cfa49fd7af2f14 64365bec0edb10\&cj_affid $=2617611 \& c j_{-}$ affname $=$ Skimlinks.

\section{Assessment, outcomes, and evaluation}

- 4Teachers.org. 4Teachers is part of ALTEC (an organization for research and development of professional learning opportunities at the University of Kansas). 4Teachers.org is a free instructional design website with teacher-creation tools and samples that can be adapted and modified, as well as an ongoing database of these samples, including lesson plans, quizzes, and calendars. Of note is the tool Rubistar (http://rubistar.4teachers. org/index.php), which allows for customized rubrics that can be downloaded, printed, or saved, with pre-populated criteria and point values for PBL milestones or summative assessment at the end of a unit. Access: http:// www.4teachers.org/.

\section{Organizational models and support}

- Center for Project-Based Learning at Worcester Polytechnic Institute (WPI) with AAC\&U. Recently launched in January 2016, the center's goal is to provide support to administrators and faculty "aiming to advance project-based learning on their campuses." WPI has a long history of supporting PBL, and this site offers both adaptable strategies and empirical evidence of the effectiveness of PBL. Access: http://wp.wpi.edu /projectbasedlearning/.

- Indiana Collaborative for PBL/ Magnify Learning. This group of educators, administrators, and higher education institutions grew out of a need to combine efforts across Indiana to provide training and certification of PBL curricular development, as well as assess educators' abilities to pro- 
mote and deliver high-quality teaching and projects in $\mathrm{K}-12$, as well as at the academic level, on the MaginfyLearning site: http:// magnifylearningin.org/. Yearly, collaborative workshops, as well as a fee-based certification, are available. Access: http://cell. uindy.edu/our-work/project-based-learning /indiana-collaborative-for-pbl/.

- NYC Department of Education. From the Division of Teaching and Learning Office of Curriculum, Standards, and Academic Engagement: "Project-Based Learning: Inspiring Middle School Students to Engage in Deep and Active Learning," is a thorough overview on PBL development, highlighting the use of the library resources and collaborating with librarians in interdisciplinary units to enhance and engage students through a wider base of support, promoting thriving learning communities. Access: http://schools.nyc.gov/documents /teachandlearn/project_basedFinal.pdf.

- Sam Houston State University, Center for Project-Based Learning. Provides resources for both K-12 and higher education, parents, and international examples of PBL; a robust glossary of key PBL terms, with links to video demonstrations at the university's College of Education; as well a webportal created by students. Access: http://www.shsu.edu/centers /project-based-learning/.

\section{Note}

1. George D. Kuh, High-Impact Educational Practices: What They Are, Who Has Access to Them, and Why They Matter (Washington, D.C.: American Association of Colleges and Universities, 2008). n

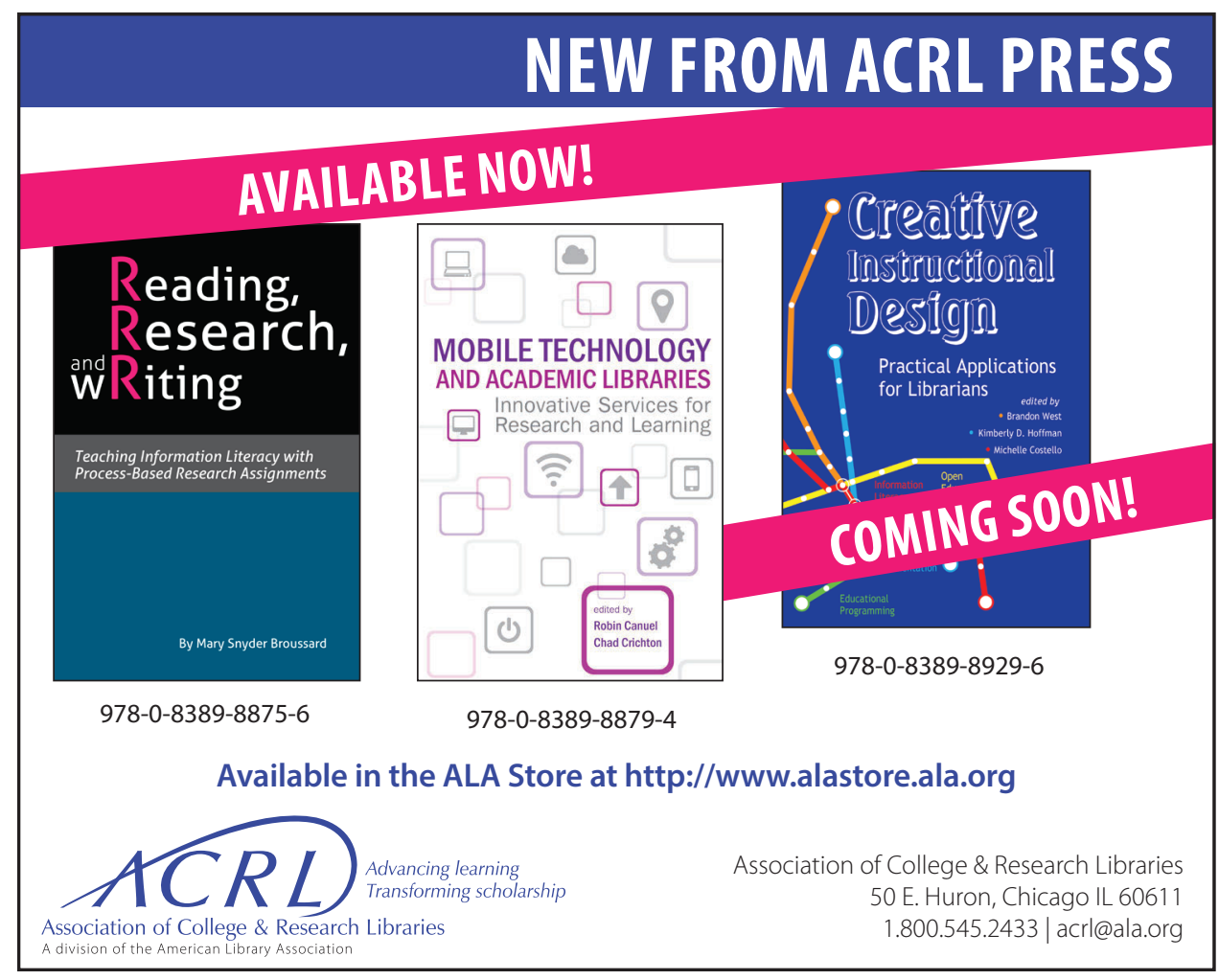

